\title{
A hospitalidade como política pública ao ius migrandi
}

\author{
La hospitalidad como política pública al ius migrandi \\ Hospitality as a public policy for ius migrandi
}

\section{Deisemara Turatti Langoski ${ }^{1}$}

\begin{abstract}
Resumo
Há movimentos migratórios desde a existência do homo sapiens, porém, nos últimos anos, estes fluxos têm sido considerados "novos" pelas dimensões em que se tem apresentado: são migrações forçadas, decorrentes de conflitos civis, políticos, bélicos, econômicos, questões climáticas. Embora haja previsão na Declaração Universal dos Direitos Humanos para a proteção de toda e qualquer pessoa ao ius migrandi, ou seja, o direito à livre circulação (artigo 13), na prática, esse direito carece de contribuições valorativas, jurídicas e, principalmente, de políticas governamentais para a eficácia e efetividade do acolhimento de migrantes e refugiados. Objetiva-se verificar os fundamentos ao direito de migrar sob o viés dos direitos humanos e a relação entre políticas públicas estatais e ações migratórias. Para esse fim, a pesquisa utiliza o método de abordagem dedutivo e a técnica da pesquisa bibliográfica. O estudo fornece uma reflexão sobre as migrações contemporâneas e a práxis da hospitalidade, sendo essa essencial para reconhecer como sujeito de direitos, qualquer pessoa, independentemente de sua condição e em respeito às diferenças, para o fortalecimento de valores cooperativos e humanos em uma sociedade democrática, multiétnica e pluralista.
\end{abstract}

Palavras-chave: Ius migrandi; Políticas Públicas; Hospitalidade.

\section{Resumen}

Hay movimientos migratorios desde la existencia del homo sapiens, pero en los últimos años, estos flujos han sido considerados "nuevos" por las dimensiones en que se ha presentado: son migraciones forzadas, derivadas de conflictos civiles, políticos, bélicos, económicos, cuestiones climáticas. Aunque hay previsión en la Declaración Universal de los Derechos Humanos para la protección de toda persona al ius migrandi, es decir, el derecho a la libre circulación (artículo 13), en la práctica, este derecho carece de contribuciones valorativas, jurídicas y, principalmente, políticas gubernamentales para la eficacia y efectividad de la acogida de migrantes y refugiados. Se pretende verificar los fundamentos al derecho de migrar bajo el sesgo de los derechos humanos y la relación entre políticas públicas estatales y acciones migratorias. Para ello, la investigación utiliza el método de enfoque deductivo y la técnica de la investigación bibliográfica. El estudio proporciona una reflexión sobre las migraciones contemporáneas y la praxis de la hospitalidad, siendo esa esencial para reconocer como sujeto de derechos, cualquier persona, independientemente de su condición y en respeto a las diferencias, para el fortalecimiento de valores cooperativos y humanos en una sociedad democrática, multiétnica y pluralista.

Palabras clave: Ius migrandi; Políticas públicas; Hospitalidad.

\begin{abstract}
There have been migratory movements since the existence of Homo sapiens, but in recent years, the dimensions in which they have been presented have considered these flows "new": forced migrations, resulting from civil, political, war, economic, climatic conflicts. Although there is provision in the Universal Declaration of Human Rights for the protection of every person in ius migrandi, that is, the right to free movement (Article 13), in practice this right lacks value, legal and, above all, policies for the effectiveness and effectiveness of the reception of migrants and refugees. The objective is to verify the foundations of the right to migrate under the human rights bias and the relationship between state public policies and migratory actions. For this purpose, the research uses the method of deductive approach and the technique of bibliographic research. The study provides a reflection on contemporary migrations and the praxis of hospitality, which is essential to recognize as a subject
\end{abstract}

\footnotetext{
${ }^{1}$ Doutora em Direito UFSC; Santa Catarina; Brasil; deiselangoski@ gmail.com
} 
of rights, any person, regardless of their condition and respect for differences, for the strengthening of cooperative and human values in a democratic society, multiethnic and pluralistic.

Keywords: Ius migrandi; Public policy; Hospitality.

\section{Introdução}

A migração humana na contemporaneidade tem acendido novas representações com relação ao vulto, à direção e aos arranjos dos seus fluxos, pois, torna visível um dramático e urgente fenômeno social, que não havia alcançado relevância tão implacável na história da humanidade como nos dias de hoje, razão pela qual o tema interessa a todas as sociedades do mundo.

A intensidade do movimento migratório foi facilitada pelos modernos e velozes meios de comunicação e de transporte, ao mesmo tempo em que contrasta com uma série de dificuldades: o progressivo fechamento das fronteiras, os insuficientes espaços sociais de acolhida, a insegurança humana, a falta de trabalho, as situações de guerra civil, conflitos internos, transfronteiriços e internacionais, discriminação racial, intolerância religiosa, degradação do meio ambiente, pobreza extrema e a busca por melhores condições de vida, acabam por expulsar milhões de pessoas de seu lugar de origem.

O trabalho divide-se em três partes, assim distribuídos: primeiramente, apresenta-se o ius migrandi que consiste em um direito reconhecido pela Declaração Universal dos Direitos Humanos (1948). Em seguida, busca-se promover a práxis da hospitalidade na perspectiva jurídica, como um dos valores cogentes ao reconhecimento do outro em suas diferenças. E, na terceira e última parte, verifica-se que o ius migrandi requer todo um processo de aceitação e acolhida, seja nas terras de destino, seja nas de origem, situação que envolve as condições da hospitalidade como política pública.

Para a produção do presente texto utilizou-se o método de abordagem dedutivo e a técnica da pesquisa bibliográfica, com o intuito de gerar uma reflexão em torno da efetivação dos Direitos Humanos para todas as pessoas residentes em um território, sendo nacionais ou não. E nesse sentido, não se pode mais pensar em uma questão que compreenda direitos como pertencentes a todas as pessoas que habitam um território.

\section{O ius migrandi: direito de mobilidade humana}


A mobilidade humana é uma forma audaciosa que as pessoas realizam para refrear os infortúnios e as adversidades migrando para outros territórios em busca de condições de sobrevivência ou como projeto de vida, a ponto de inclinar (em) todos os seus esforços a fim de obter, para si e sua família uma vida mais satisfatória, com segurança e paz, sem avaliar as implicações vindouras.

Seguindo a doutrina do jusnaturalismo de Francisco de Vitória, Ferrajoli (2010, p. 129) aborda o ius communicationis (direito de comunicação), que preleciona a existência de uma comunicação natural entre os povos. Assevera que do direito de comunicação transcorrem outros direitos: o ius peregrinandi (direito de viajar), o ius degendi (direito de permanecer), o ius commerci (o direito de comércio), o ius occupationis (o direito universal a ocupar terrenos baldios) e o ius migrandi (o direito de se mover para o novo mundo e ali adquirir a cidadania). Referidos direitos contemplados por Vitória, serviram tanto para convalidar a lógica dos colonizadores, quanto dos colonizados na história das civilizações (FERRAJOLI, 2010, p. 130).

O ius migrandi foi anunciado por Francisco de Vitória, aproximadamente quarenta anos após a descoberta da América, em seus Relectiones de Indis recenter inventis, publicado na Universidade de Salamanca, Espanha (1539), quando formulou a primeira doutrina dos direitos naturais, ao proclamar como direitos universais de todos os homens e de todos os povos o ius communicationis, o ius peregrinandi, o ius degendi, o ius commerci, o ius occupationis e o ius migrandi (FERRAJOLI, 2010, p. 32).

O aporte referente ao ius migrandi, inaugura um paradigma, cujo alicerce encontra-se na igualdade de direitos dos povos em migrar para qualquer parte do mundo e continha como justificativa que se tratava de um direito essencial para as futuras conquistas e colonizações. Francisco de Vitoria deliberou que o ius migrandi incidia em um direito natural e universal, compreendendo os direitos de viajar, emigrar e residir (peregrinandi, migrandi, degendi) e pertencem a todos os seres humanos, sendo inalienáveis e imutáveis (não-negociáveis), não devendo ser reservado ou exclusivo de alguns cidadãos.

O ius migrandi apresenta quatro dimensões: o direito a não migrar, o direito a migrar, o direito a estabelecer-se pacificamente e o direito a retornar, conforme classificação de Sancho; Navarro (2013, p. 1-10):

a) Direito a não migrar: Implica que nos Estados de origem ou de residência as pessoas tenham alcançado um desenvolvimento de igual importância em todas as suas dimensões (política, econômica, social, cultural, ambiental) de vidadigna, a fim de evitar o êxodo. 
b) Direito a migrar: Cuida que qualquer pessoa deve ser capaz de circular livre e voluntariamente por qualquer lugar, dento e fora do país de origem. Pressupõe dois aspectos: o direito de deixar o território de um Estado (emigração) e o direito de entrar no território de outro Estado (imigração).

Para Mezzadra (2012, p. 11), o direito a migração configura-se no Direito de Fuga, que exprime o anseio de evasão e a cobiça da liberdade que os movimentos migratórios revelam. A migração consiste em uma escolha pessoal, não é feita por obrigação, a pessoa simplesmente exerce seu direito de liberdade.

Sancho; Navarro (2013, p. 7) afirmam que o valor da mobilidade humana deve fazer parte do campo dos direitos de liberdade. E advertem que, faz-se necessário diferenciar as migrações individuais das migrações coletivas. No primeiro caso, elas podem ser voluntárias e, como tal, devem ser consideradas como o exercício de um direito; já as segundas, são migrações forçadas.

c) Direito a estabelecer-se pacificamente: significa o direito da pessoa trabalhar, estudar e viver no país que tenha escolhido para residir de forma pacífica. Em outras palavras, estabelecer-se de forma tranquila na atualidade deve pressupor a integração entre pessoas de nacionalidades e etnias distintas. Requer a submissão às regras do Estado receptor, o pagamento de impostos e taxas, a participação na vida política, social, cultural, econômica e pertencer a uma comunidade, o que não converge com a existência de guetos, como forma de exclusão e marginalização social.

d) Direito a retornar: pressupõe que a pessoa está no exterior e possa voltar ao Estado de origem e esse deve admiti-lo; se ele é acusado de crimes, será julgado e, se necessário, condenado. Para o retorno e necessário instituir condições de vida dignas, o que nem sempre acontece. Em numerosas ocasiões, surgem obstáculos sociais, políticos e econômicos que obstruem tal intenção² (SANCHO; NAVARRO, 2013, p. 9).

$\mathrm{O}$ ius migrandi, encontra-se previsto no artigo $13^{3}$ da Declaração Universal dos Direitos Humanos, que trata do notabilizado direito de ir e vir e prenuncia que todas as pessoas possuem o direito de circular livremente e de escolher sua residência de maneira legal, no lugar que avaliar melhor para viver. Prevê também que toda pessoa, pode abandonar a terra em que se encontra e retornar ao seu país de origem. Em suma, este dispositivo versa

\footnotetext{
${ }^{2} \mathrm{Na}$ esfera econômica, o regresso, certamente, diminuirá as remessas monetárias, importante fonte de renda para alguns Estados; a redução, muitas vezes, não são bem aceitas pelos líderes políticos, pois são os que mais se beneficiam em primeiro lugar com tais fontes monetárias (SANCHO; NAVARRO, 2013, p. 9).

${ }^{3}$ Declaração Universal Dos Direitos Humanos. "Artigo 13. 1. Todo ser humano tem direito à liberdade de locomoção e residência dentro das fronteiras de cada Estado. 2. Todo ser humano tem o direito de deixar qualquer país, inclusive o próprio, e a este regressar."
} 
sobre a liberdade de circulação. Já os artigos 18 e $19^{4}$ da Declaração de 1948, se limitam a afirmar que o direito de asilo está regulado na Convenção de Genebra; que as expulsões coletivas estão proibidas e que ninguém pode ser expulso ou extraditado a um país em que existe um sério risco de ser submetida à pena de morte, a tortura ou a tratamentos degradantes. Nessa direção Vitale (2017, p. 53) reconhece:

\begin{abstract}
Mesmo que seja importante estabelecer que todos tenham o direito de deixar qualquer país, incluindo aquele em que é cidadão, é bastante claro que $o$ ius migrandi levado a sério contempla também, como bem sabia Vitória desde 1539, a afirmação do direito de qualquer indivíduo a escolher a própria residência em qualquer parte do planeta. E todo o direito eficaz em prol de um sujeito implica um dever em prol de outro: e neste caso, o dever de o país escolhido por um indivíduo como residência estável, é de acolhê-lo como novo cidadão. (Grifos nossos).
\end{abstract}

$\mathrm{O}$ direito a migrar aparece como a extensão máxima e mais coerente do direito à livre circulação da pessoa e faz parte dos direitos de primeira geração (considerando uma hipotética gradação axiológica), seguido do direito à vida, pelo qual se encontra vinculado, mas considerando como "vida digna de ser vivida y no como simple supervivência. É a expressão máxima da libertad personal. De hecho, la posibilidad de elegir el lugar em el que se quiere vivir es la primera condición para buscar la felicidad" (VITALE, 2017, p. 55).

Reconhecer na práxis o ius migrandi como um autêntico direito na categoria dos Direitos Humanos, conforme dispõe os referidos artigos 13, cominado com os artigos 18 e 19, da Declaração Universal dos Direitos Humanos (1948), faz com que o direito soberano dos Estados não esteja acima do respeito, da defesa e da proteção dos princípios universais estabelecidos à todas as pessoas, inclusive os que encontram-se na condição de migrantes e refugiados, ainda mais quando os Estados subscreveram, internacionalmente, os pactos e declarações para a garantia destes direitos.

Aponta Vitale (2017, p. 47) que o espaço ocupado pelo ius migrandi condiz ao direito de migração e, por sinal o considera como "a faculdade de cada um dos indivíduos de atravessar as fronteiras dos estados e eleger livremente sua residência, temporária ou definitiva [...]". Todavia, como suposto "derecho fundamental novísimo" e, em resposta às condições fáticas e às motivações objetivas do massivo fenômeno migratório contemporâneo, necessário considerar como um direito em cuja realização equivale:

\footnotetext{
${ }^{4}$ Declaração Universal Dos Direitos Humanos. "Artigo 18. Todo ser humano tem direito à liberdade de pensamento, consciência e religião; este direito inclui a liberdade de mudar de religião ou crença e a liberdade de manifestar essa religião ou crença, pelo ensino, pela prática, pelo culto e pela observância, isolada ou coletivamente, em público ou em particular. Artigo 19. Todo ser humano tem direito à liberdade de opinião e expressão; este direito inclui a liberdade de, sem interferência, ter opiniões e de procurar, receber e transmitir informações e ideias por quaisquer meios e independentemente de fronteiras."
} 
(a) como uma prioridade nas necessidades econômicas e sociais do país de destino ou; (b) que depende de condições de extrema necessidade, em que está em jogo a vida dos seres humanos. Ou seja, condições que por si só tornam marginal a livre escolha: pobreza absoluta, guerra, grave perseguição política, desastres ambientais irreversíveis (VITALE, 2017, p. 47).

Todas as enunciações apresentadas refletem as dificuldades próprias de uma perspectiva teórica do ius migrandi que ultrapasse as fronteiras e, no presente permanece como mera expressão da autonomia individual do ser humano, ao invés do direito de livre circulação e de residência, assim como da plena possibilidade de exercê-lo, nos termos preconizados na Declaração Universal dos Direitos Humanos.

Deste modo, o clamor dos migrantes e refugiados em prol dos seus direitos, tem como principal documento a Declaração Universal dos Direitos Humanos de $1948^{5}$, que representa uma resposta às brutalidades perpetradas durante a $2^{\mathrm{a}}$ Guerra Mundial, em um "[...] esforço de reconstrução dos direitos humanos, como paradigma e referencial ético a orientar a ordem internacional contemporânea [...]" (PIOVESAN, 2016, p. 475).

Nesse prisma, na primeira década do século XXI, a proteção dos direitos dos migrantes e refugiados encerra, de fato, um tema chave na agenda dos Direitos Humanos, pois envolve a redefinição de concepções jusfilosóficas e éticas (a alteridade, a cidadania, etc.); reaviva valores humanitários (a generosidade, a solidariedade, a tolerância, entre outros); ao levar em consideração a existência de todo um contexto econômico, político e social a nível local, nacional e internacional que se transforma, necessitando de adaptação e reajustamento, dada a crescente intensificação dos fluxos migratórios.

Urge, (re) pensar o ius migrandi, com a proteção que a Declaração Universal dos Direitos Humanos lhe atribui, a fim de (re) significar a percepção de universalidade destes direitos, que legitimamente contemple os migrantes e refugiados, como verdadeiros sujeitos de direitos.

\section{A hospitalidade como práxis humanitária}

O século XXI principia sob a crescente internacionalização e transnacionalização das empresas privadas, do avanço da tecnologia, das questões ambientais globais e da proteção dos Direitos Humanos. Isso ocasiona a sensação de pertencimento do homem ao mundo. São consequências da globalização e acendem para uma mudança nas estruturas políticas e econômicas que dominam o mundo, ao mostrar que "Novas possibilidades se apresentam à

\footnotetext{
5 De acordo com Piovesan (2016, p. 475), “o Direito Internacional dos Direitos Humanos constitui um movimento extremamente recente na história, surgindo, a partir do pós-guerra, como resposta às atrocidades cometidas durante o nazismo."
} 
medida que as pessoas se dão conta de que, antes de pertencerem a diferentes Estados, são habitantes de um mesmo e único planeta, quase todo ele acessível” (SICILIANO, 2012, p. 115-116, grifos nossos).

Com o crescente deslocamento de pessoas ou grupos sociais para as mais diversas e distantes regiões do mundo, traz presente um tema tão antigo quanto à própria civilização humana, a hospitalidade.

Rossetto; Veronese (2016, p. 63) explicam a concepção do termo hospitalidade:

A caracterização da hospitalidade passa pelas evocações do habitar humano e, consequentemente, dos distintos momentos da história humana e de seu viver $e$ conviver, colher - a saber, ajuntar, recolher, colocar uma coisa junto de outra, contar uma coisa junto com outra, referir uma à outra, da mesma forma que esse ajuntar é um expor e um propor, um colocar à disposição e apresentar, um tornar acessível, um habitar e igualmente um estabelecer, para, então, finalmente, conferir a possibilidade de dar passagem e hospitalidade ao forasteiro-estrangeiro. (Grifos nossos)

Os elementos destacados representam as inúmeras configurações do agir humano, que compõem e estabelecem a atuação hospitaleira, sendo: viver, conviver, colher, ajuntar, expor, propor, dispor, apresentar, habitar estabelecer, dar passagem (acessar). São entonações de ação que fazem ou deveriam fazer parte da vida de qualquer ser humano na localidade de sua eleição ou ao que por circunstâncias adversas mora e coexiste.

Historicamente, a hospitalidade tem sido associada com a necessidade de disponibilizar um espaço protetor para o outro, ou seja, trata-se de um processo social, que aponta para o provimento de um lugar de recepção (alojamento, acolhida) e de tutela (amparo, segurança), pois a hospitalidade “[...] é um ato cultural, uma criação sociohistórica, e, por onde, a questão a interrogar não é a de ser ou não hospitaleiros, senão quais são os gestos, os códigos e instituições que expressam e veiculam a hospitalidade em cada tempo e lugar" (HABA; SANTAMARÍA, 2006, p. 16).

"A hospitalidade é um direito de todos e um dever para todos", pois ela materializa uma forma de cidadania genérica ${ }^{6}$, a qual deve designar uma cultura dos direitos que adentra nas mentes e nos corações de todos os cidadãos do mundo, acendendo a "comunidade dos povos" (BOFF, 2015).

Dencker (2004, p. 189) focaliza a hospitalidade ligada à prática humanista, tendo em vista que o homem é um ser social e, a partir das suas relações é que se fomentam e se estruturam as sociedades. Afirma que restabelecer o exercício da hospitalidade adentra no

\footnotetext{
${ }^{6}$ Nesta direção, Kieling (2001, p. 105) manifesta no tocante a questão da cidadania que, existe a "[...] necessidade de uma comunhão entre os trabalhadores de todos os cantos da Terra a fim de consolidar a perfeita cidadania, de vez que o propósito não pode deixar de ser o bem-estar do próximo”.
} 
âmbito das ideias, da religião, da filosofia, da ética, cuja fundamentação elementar encontrase na questão da diversidade cultural. Contempla ainda que, todas as sociedades possuem regras - morais, legais, culturais - que regulam as relações de trocas e de convivência entre as pessoas, o que corrobora que, de algum modo, acolham a uma ou mais necessidades básicas do ser humano.

Já Derrida (2003) coloca que a hospitalidade como acolhimento do outro que se aproxima. Em outras palavras, a hospitalidade se sustenta pelo deixar que o outro chegue, pelo acolhimento sem reservas, consiste em uma ação de generosidade para com o outro. A hospitalidade que se concebe, condiciona-se aos direitos e deveres que precisam ser seguidos pelo que chega e pelo que acolhe.

Aliado ao ser e estar hospitaleiro figura as "[...] muitas formas como o migrante vivencia a acolhida individualmente e através de suas redes de sociabilidade" (DORNELAS, 2007, p. 3). Referidas ações, possuem um valor essencial para o bem-estar dos migrantes e refugiados, uma vez que trazem padrões culturais e sociais que são sua identidade e que persistem nas gerações.

E preciso mediar este encontro entre a hospitalidade e os padrões de identidade de cada povo, ao trazer presente uma cultura política capaz de transformar os julgamentos formais e rígidos que regulam as práticas políticas e sociais, seja do Estado em suas normas restritivas em relação aos migrantes, seja em sociedade com práticas mais colaborativas e acolhedoras (DORNELAS, 2007, p. 3).

A utilização de modelos de atuação hospitaleira são estratégias para a integração entre os povos, afim de minimizar as dificuldades e os problemas decorrentes da adaptação de pessoas em um novo país:

As interações sociais constituem a trama das relações sociais. A impregnação nesses códigos de interação social é onipresente na vida das pessoas. Esta é a razão das dificuldades e obstáculos que devem ser transpostos numa situação de contato entre culturas diferente e, especialmente, no caso desse grupo que se viu forçado a abandonar os seus costumes, os seus amigos (KHOURI; BUENO, 2007, p. 42).

Essa concessão mútua de espaços ao outro, ou seja, esse padrão de hospitalidade tem o condão de propiciar benefícios, tanto aos estrangeiros, quanto aos nacionais, eis que "[...] se beneficiaram com o contato [...] por terem se libertado de exageros e no abrandamento da pressão social no cumprimento de certos padrões de sociabilidade" (KHOURI; BUENO, 2007, p. 42). Compreende-se que a atuação com hospitalidade encontra-se na constituição e na conservação das relações sociais, valores próprios de cada povo, os quais se alteraram no decurso do tempo, influenciados pela modernidade e pela globalização. 
Corrobora Rossetto; Veronese (2016, p. 63) quando aduzem:

A dinâmica da hospitalidade acompanha o homem nos seus movimentos, deslocamentos e intenções, de ir e vir, influenciando - positivamente e negativamente - tanto a sociedade de origem quanto a de acolhimento, colocando em circulação saberes, culturas, economias, trocas e famílias inteiras e encontra-se associada à política migratória.

Esta demanda perfaz-se em um impasse oriundo da globalização, porque é de difícil equacionamento, uma vez que "transcende o poder do Estado-Nação e demanda uma solução pensada e levada a efeito a partir de uma instância de governança global da humanidade" (BOFF, 2005, p. 112-113), tendo em vista que são muitos os Estados provocados para a implementação de políticas publicas voltadas aos Direitos Humanos, com objetivos humanitários ao acolhimento e enfrentamento do problema mundial das migrações.

As migrações, hoje em dia, estão suscitando a construção de uma sociedade integrada na tolerância, na prevenção, na proteção e na defesa dos Direitos Humanos, mas também, no esforço para o encontro das culturas e do diálogo, a fim de favorecer, no respeito de cada pessoa, a troca e uma nova relacionalidade baseada na paz e na justiça. Este encontro e enriquecimento entre culturas distintas verificam-se, não na abdicação da própria identidade, mas na busca de desígnios que sejam comuns ou de uma comum solidariedade (CANDATEN, 2007, p. 33). Este espírito de cooperação partilha e acolhida, consiste no objetivo máximo para a convivência em uma sociedade cada vez mais plural, diversificada e multiétnica.

Assevera Candaten (2007, p. 38), que é preciso reconhecer o outro acolhendo as diversidades culturais, uma vez que estas (linguajar, cultura, culinária, forma de agir, prática religiosa) compõem o "tecido cultural"7, que integra a "verdade contida na diferença do outro", em sua subjetividade, elementos estes que se apresentam como a abertura imprevista para o novo:

[...] acolher a diversidade, pressupõe um desejo e uma atitude em direção ao outro, que supera preconceitos, distâncias e indiferenças. Acolher ${ }^{8}$ o migrante é antes uma atitude mental e espiritual que toca a interioridade da pessoa. Sem esta disposição interior, ele continuará habitando na soleira, como um estranho. O reconhecimento da diversidade é um recíproco enriquecimento, um intercâmbio dos bens morais, étnicos, culturais, religiosos, que levam a uma complementação e aperfeiçoamento mútuos. Essa acolhida é expressão de nobreza humana e revela a disposição em conceder aos vários grupos étnicos iguais oportunidades, liberdade de expressão e, sobretudo, de realizarem-se segundo as características e índoles próprias (CANDATEN, 2007, p. 38, grifos nossos).

\footnotetext{
${ }^{7}$ Esclarece Candaten (2007, p. 38) que nenhuma cultura é absoluta na sua forma de manifestar-se, seja histórica ou concretamente e, por este motivo, encontra-se em constante diálogo cultural.

8 " $O$ verbo 'acolher' caracteriza a abertura e a disponibilidade típica das relações fraternas e mais que um contato passageiro, trata-se de uma alegre comunhão espiritual, que permite ao hóspede que chega, a partilha daquilo que é mais profundo e vital" (CANDATEN, 2007, p. 38).
} 
Esse processo de acolhida das diferenças requer o exercício da alteridade, no sentido de um esvaziamento dos pré-conceitos, dos pré-julgamentos, da observação de si e das próprias práticas sociais e culturais, a fim de que se expanda ao reconhecimento e aceitação do outro e, quando as diferenças são harmonizadas, cria-se um ambiente de hospitalidade e propício para práticas humanitárias.

\section{A hospitalidade como política pública ao ius migrandi}

Os processos migratórios adotaram um contorno diferenciado após as Guerras Mundiais, em particular, a Segunda Grande Guerra (1945) e, de maneira especial, na última década intensificou-se de forma veemente, o fluxo internacional de pessoas para longas distâncias e para diferentes partes do mundo.

O paradoxo da globalização associada ao aumento das desigualdades econômicas e sociais, ao desenvolvimento dos meios de comunicação e informacional, ao incremento do sistema de transportes, propiciou a abertura das fronteiras aos capitais, bens e serviços, mas não às pessoas. Essa situação ocasiona intensos dramas sociais (desemprego, fome, violências, entre outros), determinadas pelo próprio homem, e que poderiam ser evitáveis ou amenizadas se "a solidariedade humana tivesse primazia sobre o egoísmo individual" (TRINDADE, 2008, p. 54), se houvesse por parte dos governantes ações para a implementação de políticas públicas preventivas e protetivas.

Destes acontecimentos, insurgem e se intensificam o fluxo massivo de migrações forçadas, em que derivam graves sequelas humanas, políticas, econômicas e sociais, dificultando a implementação dos preceitos internacionais de proteção ao ser humano. Fato incontestável é que a entrada acessível para a circulação de pessoas continua a ser uma utopia a ser conquistada, pois o efeito globalizante na sociedade segrega, seleciona e exclui, por que:

Se, por um lado, a globalização exerce um forte estímulo às migrações, uma vez que intensifica o fluxo de informações sobre padrões de vida e oportunidades nos países industrializados, tal estímulo não é acompanhado por um aumento de oportunidades. Se, por um lado, o fluxo de capital e mercadorias é incentivado, por outro, aumentam-se as restrições ao fluxo de pessoas (VASCONCELOS; BOTEGA, 2015, p. 7).

A mobilidade humana é uma realidade do século XXI e não pode ser ignorada nos programas governamentais nacionais e internacionais: migrantes, imigrantes, emigrantes, refugiados, deslocados e apátridas fazem parte de um mesmo processo histórico: lutam pelo respeito e dignidades lutam pelos direitos humanos, lutam pelo direito de ir e vir, lutam para serem "cidadãos do mundo". 
Neste cenário, os intensos e distintos fluxos migratórios, têm desafiado os Estados, as organizações internacionais e a sociedade civil em geral, a apoiar e indicar instrumentos legais e a fomentar políticas públicas que amparem as pessoas em seus deslocamentos, permanentes ou temporários, de curta ou longa distância, não importando as motivações, mas com a convicção de que a migração configura-se um direito humano (VASCONCELLOS; BOTEGA, 2015, p. 7-8).

Corroboram Milesi e Lacerda (2007, p. 9) ao afirmar que o tema "É, sim, uma questão complexa, urgente e necessária, que deve ter prioridade de inserção na agenda dos direitos humanos", bem como no campo das discussões de políticas públicas e ações efetivas e eficazes para solucionar esse desafio humanitário. Nesse sentido, as práticas da hospitalidade tornam possível a integração de todas as pessoas em sociedade e faz com que os sujeitos sejam reconhecidos em seus direitos e no cumprimento de seus deveres em comunidade.

Soares (2007, p. 14), seleciona e apresenta duas contradições que carecem de entendimento, posto que são de extrema importância para compreender a hospitalidade: “[...] primeiro, a contradição inclusão econômica/exclusão política; segundo, a contradição monólogo da gestão migratória pelos Estados de destino/diálogo das sociedades de destino com os movimentos sociais dos migrantes." A primeira contradição, pode ser reduzida nos seguintes parâmetros:

[...] os Estados Nacionais, especialmente os considerados "desenvolvidos" recebem mão-de-obra não-qualificada para preencher os cargos que a população nativa não está disposta a ocupar (por exemplo tarefas ligadas à limpeza pública e privada), ao mesmo tempo que criam medidas restritivas à integração social e política dos migrantes e refugiados ilegais, excluindo-os tanto do processo decisório quanto dos benefícios das políticas públicas (SOARES, 2007, p. 14).

Uma "política migratória coerente", fundamentada em Direitos Humanos, pode se tornar uma cilada, pois visa, apenas, os interesses dos países desenvolvidos, motivo pelo qual centraliza o apoio aos movimentos de migrantes temporários, os quais apresentam como diferencial o envio de remessas, que, além de produzir atividades econômicas no país de destino, sanando o problema do desemprego, contribuem para o combate à pobreza dos países de origem (PATARRA, 2006, p. 7-24). Em outro sentido, refere-se que, o migrante ideal, é aquele que mantém conduta passiva diante das políticas migratórias, atendendo os interesses econômicos e geopolíticos do país de destino.

A outra contradição diz respeito à objetificação dos migrantes e refugiados. Para tanto esclarece Soares (2007, p. 14): “[...] face ao monólogo dos Estados de destino gestores, constroem-se no mundo contemporâneo diálogos mais amplos sobre o tema migrações, nos quais os migrantes se tornam sujeitos dos debates.” Em outras palavras, as instituições e 
Estados ditam as regras e condições do migrante e refugiado no país de destino, sem envolvêlo nos temas de seu interesse. Esta situação tem o condão de ocasionar inúmeros conflitos, revoltas e dissabores no meio social.

Contudo, existem outros fatores, como as identidades étnicas, a religião, a cultura, o tipo de deslocamento em curso (coletiva, forçada, voluntária, entre outras), por representarem vetores de sociabilidade, influenciam as relações de hospitalidade/hostilidade. ${ }^{9}$

O fenômeno contemporâneo das migrações põe em proeminência princípios assegurados por inúmeros Estados, como o direito de cruzar as fronteiras, a liberdade de locomoção e circulação dentro e fora do seu país de origem, inclusive de proteção, os quais estão dispostos nos artigos 13 e 14 da Declaração Universal dos Direitos Humanos de 1948. ${ }^{10}$

A Declaração Universal dos Direitos Humanos concebeu uma política do Direito e, estes valores possuem um significado que indica para a "direção de dever ser", ao esclarecer que "[...] o Direito é uma expressão do mundo da cultura, onde o valor tem um suporte na realidade, mas tem um significado, uma direção que aponta para um caminho" (LAFER, 2017). Motivo pelo qual a agenda das migrações, precisa ser incorporada no plano local, nacional e internacional, pois a presença de migrantes e refugiados em novos territórios,

[...] viabilizaram a ideia força, que é uma ideia de Hannah Arendt, de que o "direito a ter direitos" só poderia começar a efetivar-se se prevalecer o direito de todo ser humano à hospitalidade universal. Eu insisto que neste final de século, e no início do milênio, esta noção de hospitalidade universal significa que as pessoas precisam estar à vontade e em casa no mundo (LAFER, 2017).

Observa-se que o direito universal à hospitalidade não está sendo assegurado, pois é crescente o número de situações de exclusão social e de marginalidade (LAFER, 2017), motivo pelo qual, faz-se imperioso que a Declaração Universal dos Direitos Humanos, seja de fato implementada e garantida a este grupo de pessoas.

A hospitalidade consiste em uma qualidade e uma habilidade humana, capaz de promover a mutação da natureza relacional dos homens. É cogente, que na contemporaneidade, seja adotado e exercido em sua plenitude esta ação de mútua acolhida, de abertura, de convivência no ambiente com os migrantes, que presume uma postura de alteridade. Explica Boff (2005, p. 29) que, o ser humano, por natureza, é interdependente, ou seja, não consegue viver e sobreviver sem estar em comunidade, pois “[...] o destino comum

\footnotetext{
${ }^{9}$ A título de exemplo a hostilidade dos paulistas aos nordestinos e bolivianos.

${ }^{10}$ Declaração Universal dos Direitos Humanos. Artigo 14. §1. Toda pessoa, vítima de perseguição, tem o direito de procurar e de gozar asilo em outros países. §2. Este direito não pode ser invocado em caso de perseguição legitimamente motivada por crimes de direito comum ou por atos contrários aos propósitos e princípios das Nações Unidas.
} 
foi globalizado; [...]. Estamos definitivamente vinculados uns aos outros. Essas visões necessárias nos dão conta da singularidade de nosso momento histórico".

A comunidade evoca tudo o que as pessoas sentem falta na atualidade e que constitui como necessário a fim de que possam viver em segurança. “A segurança é uma condição necessária do diálogo entre as culturas. Sem ela, há pouca chance de que as comunidades venham a abrir-se umas às outras e a manter uma conversa que venha a enriquecê-las e a estimular a humanidade de sua união. Com ela, as perspectivas da humanidade parecem brilhar" (BAUMAN, 2003, p. 128).

Pensar a vida em comunidade, recuperar a segurança, promove a necessidade de pensar ações orientadas para a responsabilidade em e com os Direitos Humanos de maneira universal e com demandas voltadas para o respeito, a proteção e o cumprimento desses direitos, especialmente, os que dizem respeito às milhares de pessoas que, diuturnamente, se veem obrigadas ou são, literalmente, expulsas de seus lares, em face dos graves conflitos civis e religiosos ou até mesmo às desventuras socioeconômicas e ambientais que assolam inúmeros países do mundo todo, de grande escala, com que a apreensão, deste início de século XXI, seja a impetuosa mobilidade humana.

Ao mesmo tempo, é parte essencial atentar, cuidadosamente, para a práxis da hospitalidade, adequando-a aos processos migratórios e os ecos deste fenômeno na sociedade globalizada. Porque a hospitalidade "[...] é feita de teias de inter-retro-relações e de cadeias de solidariedades includentes". Porquanto, "todos os seres foram hospitaleiros uns para com os outros", e, com uma visão ampla, exprime que "O universo continua a se expandir e a criar ordens cada vez mais complexas, [...] porque todos se comportam como hospedeiros, coexistem, con-vivem e cooperam para tal produção" (BOFF, 2005, p. 103).

A questão primordial, gira em torno da criação de dinâmicas de convivência em tempos de globalização, de modo inteligente e criativo e de vindicar possibilidades teóricopráticas a fim de concretizar a proposta do "estar numa comunidade", frente à dura realidade vigorante na atualidade. Equivale dizer que é uma medida imperiosa a aceitação, o resguardo e a hospitalidade para que as pessoas oriundas deste fenômeno da mobilidade forçada ou não, ao ingressar em um país distinto e, por vezes, distante geograficamente e na maioria das vezes, adverso culturalmente, sintam-se acolhidas e que possam ter seus direitos assegurados pelo Estado, bem como, sejam reconhecidas, de forma equitativa, como sujeitos cidadãos.

$\mathrm{Na}$ realização de aludidas empreitadas, compatibiliza-se a viabilidade da utopia da comunidade, uma vez que "Sentimos falta da comunidade porque sentimos falta de segurança, qualidade fundamental para uma vida feliz, mas que o mundo que habitamos é cada vez 
menos capaz de oferecer e mais relutante em prometer" (BAUMAN, 2003, p. 129). Ademais, acrescenta o autor que,

Se vier a existir uma comunidade no mundo dos indivíduos, só poderá ser (e precisa sê-lo) uma comunidade tecida em conjunto a partir do compartilhamento e do cuidado mútuo; uma comunidade de interesse e responsabilidade em relação aos direitos iguais de sermos humanos e igual capacidade de agirmos em defesa destes direitos (BAUMAN, 2003, p. 134, grifos nossos).

Estes termos revelam a base de uma mutação humano-social, ainda quimérica, eis que de forma geral, as pessoas estão egocêntricas e competitivas, contudo, a utopia impera como uma expectativa de reavivar e retomar a vida tecida no conjunto, partilhando direitos e deveres equitativos, garantidos por normas onde impera a justiça social, em que as responsabilidades assumidas e os cuidados sejam cultivados de forma recíproca e que todos os seres humanos, independente das fronteiras, sejam de fato e de direito, considerados, como legítimos cidadãos do mundo.

\section{Conclusões}

A migração expõe novos padrões no século XXI, sendo que esse processo provoca consideráveis transformações no modo de viver de todas as pessoas. Todavia, ao mesmo tempo, em que exista a mobilidade humana, de forma mais acessível, coexistem obstáculos à mesma e, esta contradição vislumbra-se na recusa ao direito da livre circulação e sua inserção nos processos sociais, econômicos das sociedades.

A ativação dos controles migratórios apresenta sentidos emblemáticos, uma vez que a mobilidade humana pelas fronteiras dos países concebe um novo modelo de estratificação social, geram inúmeras dificuldades político-sociais e coloca em xeque as concepções da liberdade e da igualdade das pessoas. Fato é que a presença de fronteiras políticas, físicas, culturais e ideológicas, transforma o migrante e o refugiado em um verdadeiro problema, seja para o país de origem, seja para o país de destino.

O ius migrandi, encontra-se previsto no artigo 13 da Declaração Universal dos Direitos Humanos, que trata do direito de ir e vir e prenuncia que todas as pessoas possuem o direito de circular livremente e de escolher sua residência de maneira legal, no lugar que avaliar melhor para viver. Prevê que toda pessoa, pode abandonar a terra em que se encontra e retornar ao seu país de origem.

Reconhecer na práxis o ius migrandi como um autêntico direito na categoria dos Direitos Humanos, faz com que o direito dos Estados não esteja acima do respeito, da defesa e da proteção aos princípios universais estabelecidos à todas as pessoas, ainda mais quando os 
Estados subscreveram, os pactos e declarações para a garantia destes direitos.

Os movimentos migratórios são complexos e dinâmicos. Sua complexidade deriva tanto das causas, quanto das consequências desta mobilidade humana. O notável aumento dos fluxos migratórios mundiais pode ser justificado por diversos fatores, mas nem sempre a decisão de migrar é tomada livremente.

Todos migrantes ou refugiados, independentemente do seu status jurídico perante a lei do país de trânsito ou do país de destino, possuem os mesmos direitos e deveres que qualquer outro cidadão, sendo que as legislações dos Estados não podem incluir em suas ordens legais preceitos que contrariem o disposto na Declaração Universal dos Direitos Humanos, bem como o que consta nos tratados, convenções e pactos internacionais, pois os princípios dos Direitos Humanos, são válidos e legítimos à quaisquer pessoas, sejam elas migrantes ou não e, devem ser observados e respeitados.

Aspira-se que a sociedade e o Estado aceitem a diversidade social e cultural, somente de tal modo será possível vislumbrar a práxis de uma nova relacionalidade humana imbuída de conceitos éticos. Este ideal, hoje, é completamente incompatível e conflitante com o processo da globalização.

É primordial a criação de políticas públicas criativas a fim de vindicar possibilidades teórico-práticas para que migrantes e refugiados possam sentir "estar numa comunidade". Equivale dizer que é uma medida imperiosa a aceitação, o resguardo e a hospitalidade para que as pessoas oriundas do fenômeno migratório, ao ingressar em um país distinto, por vezes, distante geograficamente e na maioria das vezes, adverso culturalmente, sintam-se acolhidas e que possam ter seus direitos assegurados pelo Estado de forma equitativa.

Por meio da atuação com hospitalidade, possibilita-se o reconhecimento da cidadania e da dignidade dos migrantes e refugiados que ao integralizar grupos e estabelecer-se em comunidade requer sejam considerados sujeitos de direitos, acatando a sua multiculturalidade em seus distintos matizes.

Em face da abissal mobilidade humana dos últimos anos e a imprecisão da postura dos Estados em que os migrantes e refugiados entram em busca de segurança e para melhores condições de vida, é medida emergente, tendo por baldrame os preceitos dos Direitos Humanos, seus pactos e convenções, uma visão renovada para revivificar valores morais e éticos do ser humano, a fim de consagrar o ius migrandi. 


\section{Referências}

BAUMAN, Z. Comunidade: a busca por segurança no mundo atual. Tradução de Plínio Dentzien. Rio de Janeiro: Zahar, 2003.

BOFF, L. A hospitalidade: direito de todos e dever para todos. In: Jornal do Brasil, 12 out. 2015. Disponível em: http://www.jb.com.br/leonardo-boff/noticias/2015/10/12. Acesso em: 23 jan. 2017.

. Virtudes para um outro mundo possível. Hospitalidade: direito e dever de todos. V. 1. Petrópolis/RJ: Vozes, 2005.

CANDATEN, A. Acolhida ao migrante: um valor sagrado. In: Travessia - revista do migrante. Ano XX, n. 57, jan./abr., 2007, p. 33-38. São Paulo: Maxprint, 2007.

DECLARAÇÃO UNIVERSAL DOS DIREITOS HUMANOS. Adotada e proclamada pela resolução 217 A (III) da Assembleia Geral das Nações Unidas em 10 de dezembro de 1948. Unesco (site). Disponível em: http://unesdoc.unesco.org. Acesso em: 14 jan. 2017.

DENCKER, A. de F. M. (Coord.). Planejamento e gestão em turismo e hospitalidade. São Paulo: Thomson, 2004.

DERRIDA, J. Anne Dufourmantelle convida Jacques Derrida a falar da hospitalidade. Tradução de Antonio Romane. São Paulo: Escuta, 2003.

DORNELAS, S. M. Receber e incorporar o diferente. In: Travessia - revista do migrante. Ano XX, n. 58, mai./agos. 2007, p. 3. São Paulo: Maxprint, 2007.

FERRAJOLI, L. Derechos y garantías. La ley del más débil. Traducción de Perfecto Andrés Ibáñez y Andrea Greppi. 7. ed. Madrid: Trotta, 2010.

HABA, J. de la; SANTAMARÍA, E. Migraciones, espacios urbanos y hospitalidade. In: Travessia - revista do migrante. Ano XIX, n. 54, jan./abr., 2006, p. 12-17. São Paulo: Peres, 2006.

KHOURI, D.; BUENO, M. S. Hospitalidade a qualquer hora, hospitalidade a qualquer tempo! In: Travessia - revista do migrante. Ano XX, n. 58, mai./agos. 2007, p. 37-42. São Paulo: Maxprint, 2007.

KIELING, C. A. Manifesto da cidadania. Caxias do Sul/RS: Maneco Livraria \& Editora, 2001.

LAFER, C. Globalização econômica, políticas neoliberais e os direitos econômicos, sociais e culturais. DHNET [on line]. Disponível http://www.dhnet.org.br/direitos/textos/globalizacao_dh/lafer1.html. Acesso em: 23 fev. 2017.

MEZZADRA, S. Direito de fuga: Migrações, cidadania e globalização. Tradução de Ricardo Noronha. Lisboa: Unipop, 2012.

MILESI, R.; LACERDA, R. (Org.) Políticas públicas para las migraciones internacionales: 
migrantes y refugiados. 2. ed. ACNUR; IMDH; CDHM. Brasília: Alliance Gráfica, 2007.

PATARRA, N. L. Migrações Internacionais: teorias, políticas e movimentos sociais. In: Revista instituto de estudos avançados da Universidade de São Paulo, v. 20, n. 57, p. 7-24, São Paulo, 2006.

PIOVESAN, F. Direitos Humanos e o direito constitucional internacional. 16. ed. rev. amp. atual. São Paulo: Saraiva, 2016.

ROSSETTO, G. M. de F.; VERONESE, J. R. P. Ética, direito e hospitalidade: viver e atuar na esfera da "casa comum". In: MACHADO, C. A. A.; ANDRADE, F. G. de; LOPES, P. M. Caderno de Anais [on line]. III Congresso internacional comunhão e direito: ética, direito e democracia - em busca de um novo paradigma de justiça, p.59-69. Caruaru/PE: ASCESUNITA, 2016.

SANCHO, Á. G. C.; NAVARRO, P. A. Contenido y límites del "ius migrandi". In: Revista electrónica iberoamericana, v. 7, n. 2, 2013, p. 1-10. Disponível em: http://www.urjc.es/ceib. Acesso em: 03 mar. 2017.

SICILIANO, A. L. O papel da universalização dos Direitos Humanos e da migração na formação da nova governança global. In: Revista SUR - revista internacional de Direitos Humanos [on line]. Conectas Direitos Humanos, v. 9, n. 16, jan/2012, p. 115-131. Disponível em: http://www.conectas.org/Arquivos/edicao/publicacoes/publicacao-2014631122438417350853.pdf. Acesso em: 03 abr. 2017.

SOARES, F. A. M. Metecos contemporâneos: hospitalidade, política e subjetividade na Grécia antiga e no mundo globalizado. In: Travessia: revista do migrante. Ano XX, n. 58, mai./agos. 2007, p. 13-18. São Paulo: Maxprint, 2007.

TRINDADE, A. A. C. Deslocados e a proteção dos migrantes na legislação internacional dos Direitos Humanos. In: Caderno de debates refúgio, migrações e cidadania, n. 3, nov, 2008, p. 53-93. Brasília: UNHCR-ACNUR: IMDH, 2008.

VASCONCELOS, A. M. N.; BOTEGA, T. Apresentação. In: VASCONCELOS, A. M. N.; BOTEGA, T. (Org.). Política migratória e o paradoxo da globalização. Porto Alegre: ediPUCRS, 2015. (Série Migrações - 19).

VITALE, E. Derecho a migrar: el cumplimento de la edad de los derechos? Tradução de Pamela Rodriguez Padilla. In: Biblioteca jurídica virtual del instituto de investigaciones juídicas de la UNAM [recurso eletrônico], p. 47-63. Disponível em: http://derecho.unam.mx. Acesso em: 13 mar. 2017. 
RELACult - Revista Latino-Americana de Estudos em Cultura e Sociedade

Revista Latinoamericana de Estudios en Cultura y Sociedad | Latin American Journal of Studies in Culture and Society V. 05, ed. especial, abr., 2019, artigo $n^{\circ} 1101$ | claec.org/relacult | e-ISSN: 2525-7870 